\title{
Annona atemoya Leaf Extract Improves Scopolamine-Induced Memory Impairment by Preventing Hippocampal Cholinergic Dysfunction and Neuronal Cell Death
}

\author{
Eunjin Sohn ${ }^{1, *}$, Hye-Sun Lim ${ }^{1} \oplus$, Yu Jin Kim ${ }^{1,2} \oplus$, Bu-Yeo Kim ${ }^{1}$ and Soo-Jin Jeong ${ }^{1, *}$ \\ 1 Clinical Medicine Division, Korea Institute of Oriental Medicine, Daejeon 34054, Korea \\ 2 College of Pharmacy, Chungnam National University, Daejeon 34134, Korea \\ * Correspondence: ssen4022@kiom.re.kr (E.S.); sjijeong@kiom.re.kr (S.-J.J.); Tel.: +82-42-868-9562 (E.S.); \\ $+82-42-868-9651$ (S.-J.J.)
}

Received: 14 June 2019; Accepted: 17 July 2019; Published: 19 July 2019

\begin{abstract}
We explored the preventative effect of Annona atemoya leaf (AAL) extract on memory impairment in a scopolamine (SCO)-induced cognitive deficit mouse model. Fifty-eight mice were randomly divided into six groups and orally treated with AAL extract at $(50,100$, or $200 \mathrm{mg} / \mathrm{kg}$ ) or tacrine (TAC) for 21 days. Memory deficits were induced by a single injection of $1 \mathrm{mg} / \mathrm{kg} \mathrm{SCO}$ (i.p.) and memory improvement was evaluated by using behavioral tests such as the passive avoidance task and Y-maze test. The levels of cholinergic functions, neuronal cell death, reactive oxygen species, and protein expression related to hippocampal neurogenesis were examined by immunohistochemical staining and western blotting. The administration of AAL extract improved memory impairment according to increased spontaneous alternation in the Y-maze and step-through latency in passive avoidance test. AAL extract treatment increased the acetylcholine content, choline acetyltransferase, and acetylcholinesterase activity in the hippocampus of SCO-stimulated mice. In addition, AAL extract attenuated oxidative stress-induced neuronal cell death of hippocampal tissue. In terms of the regulatory mechanisms, AAL extract treatment reversed the SCO-induced decreases in the expression of Akt, phosphorylation of cAMP response element binding protein, and brain-derived neurotrophic factor. Our findings demonstrate that AAL extract has the ability to alleviate memory impairment through preventative effect on cholinergic system dysfunction and oxidative stress-related neuronal cell death in a SCO-induced memory deficit animal model. Overall, AAL may be a promising plant resource for the managing memory dysfunction due to neurodegenerative diseases, such as Alzheimer's disease (AD).
\end{abstract}

Keywords: memory impairment; scopolamine; acetylcholinesterase; Annona atemoya leaf; neurodegenerative diseases

\section{Introduction}

Dementia, which is characterized by aging-related memory and cognitive dysfunction and includes Alzheimer's disease (AD), is becoming a more common public health problem as the lifespan of humans increases in modern industrial society [1,2]. Although the number of individuals with these diagnoses is gradually increasing, no curative medical treatment for dementia has been developed or approved by the US Food and Drug Administration (FDA), and drugs for AD provide only symptom relief [3]. Memory deficit is the most common symptom of neurodegeneration and results from neuronal dysfunction and neuronal loss in brain tissues, particularly in the hippocampal region [4]. It is generally accepted that $\mathrm{AD}$ is a complex neurodegenerative disease of multiple pathologies 
associated with central cholinergic system degeneration and oxidative stress [5]. Changes in cholinergic system activities are most strongly correlated with memory loss and cognitive impairments [6]. Additionally, cumulative evidences support the role of oxidative damage in the pathogenesis of $\mathrm{AD}$, and neuronal degeneration in $\mathrm{AD}$ patients is associated with oxidative damage to all biomacromolecule types [7]. Various acetylcholinesterase (AChE) inhibitors, such as tacrine (TAC), donepezil, and rivastigmine, have been used as medications for AD patients [8]. However, all these drugs have limited effectiveness against AD due to their loss of efficacy and toxic side effects as the disease progresses [9-11]. There is currently no available satisfactory treatment to cure AD. Therefore, alternative and complementary therapies need to be developed for AD.

Annona atemoya, a fruitful plant of the annonacear family, is a hybrid of cherimoya (A. cherimola) and sugar apple (A. squamosal), and has temperature and humidity tolerance suitable for cultivation in tropical climates [12]. Moreover, economically, this genus is the most important of the family Annonaceae due to its edible fruits and medicinal properties [13-15]. Additionally, A. atemoya is cultivated and distributed in Jeju in Korea, Taiwan, and tropical areas such as Cuba and Jamaica [16,17]. Previous studies suggested that flavonoid isolated from A. atemoya fruit has anticancer activity conferred by reducing intracellular cAMP levels and inhibiting hepatocarcinoma cell proliferation $[18,19]$. Moreover, Yi et al. showed that an extract of $A$. atemoya seed exhibits antiangiogenic potential by regulating angiogenic pathways in vitro and in vivo [20]. Recently, other studies have reported that extracts from the leaves and stems of A. atemoya [21], as well as seven alkaloids from A. atemoya leaves identified by a series of spectrometric methods [22], exert antioxidant and antimicrobial activity.

However, there is no report on the biological activity of AAL for treating neurodegenerative conditions. In this study, we investigated whether ethanol extract from AAL exerts the preventative effect on scopolamine (SCO)-induced memory deficits in a mouse model. Additionally, the effects of AAL on neuronal dysfunction and neuronal loss were investigated to explain the underlying mechanisms.

\section{Results}

\subsection{High-Performance Liquid Chromatography (HPLC) Determination of the Two Standard Compounds in $A A L$}

We used the optimized HPLC method to simultaneously determine the two standard compounds in AAL. We obtained good separation chromatograms using mobile phases consisting of $0.1 \%(v / v)$ aqueous trifluoroacetic acid (TFA) (A) and acetonitrile (B). The UV wavelengths for detecting compounds were $254 \mathrm{~nm}$. Using the established HPLC methods, the two standard compounds were resolved within $30 \mathrm{~min}$. The retention times of rutin and isoquercitrin were 27.18 and $28.47 \mathrm{~min}$, respectively. Three-dimensional HPLC chromatogram of the AAL extract is presented in Figure 1. The amounts of the two major compounds rutin and isoquercitrin were 16.65 and $2.09 \mathrm{mg} / \mathrm{g}$, respectively.

\subsection{Effect of AAL Extract on Memory Deficit in SCO-Treated Mice}

To evaluate whether AAL extract enhances the recovery from cognitive deficit, SCO-induced cognitive deficit model mice performed PAT and Y-maze tests (Figure 2A). The SCO-treated group (SCO group) exhibited markedly reduced passive avoidance latency compared with the normal (NOR) group $(p<0.01)$. In contrast, AAL extract treatment significantly increased these latencies compared with the SCO group in a dose-dependent manner (Figure 2B). The deficit in spontaneous alternations in the Y-maze test was significantly reversed in a dose-dependent manner in the SCO and AAL extract-treated group (AAL group) compared with the SCO-injected group (Figure 2C). The SCO and TAC-treated group (TAC group) also exhibited a marked attenuation of SCO-induced memory deficit. TAC treatment was used as a positive control. No significant difference was observed in the number of arm entries among the experimental mouse groups (Figure 2D). 


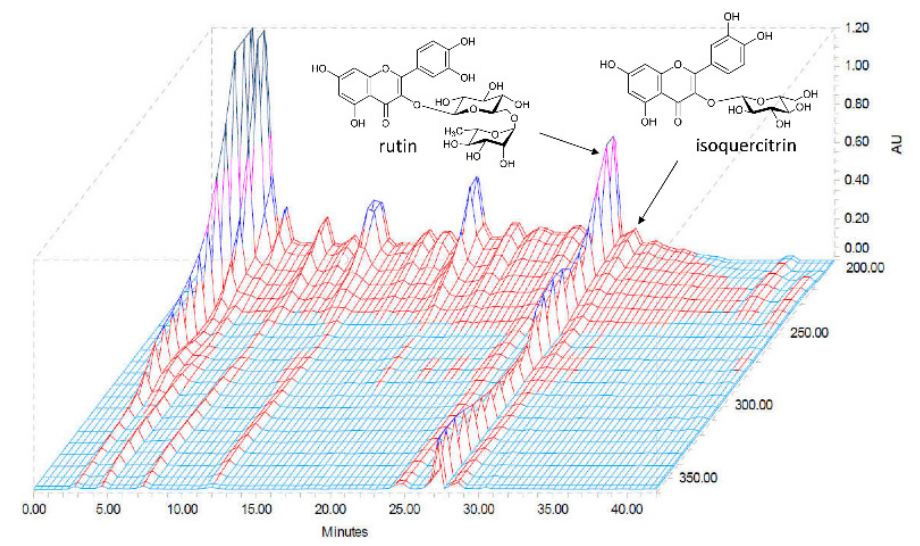

Figure 1. Three-dimensional HPLC chromatogram of Annona atemoya leaf (AAL) ethanol extract. A qualitative and quantitative analysis was performed by using HPLC. The compounds were identified by their retention times and UV spectrums relative to reference substances.

(A)

(A)

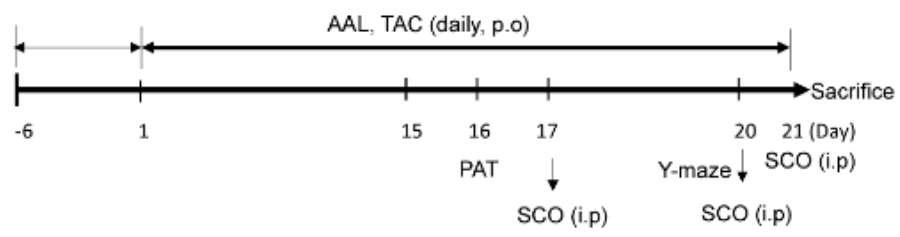

(B)

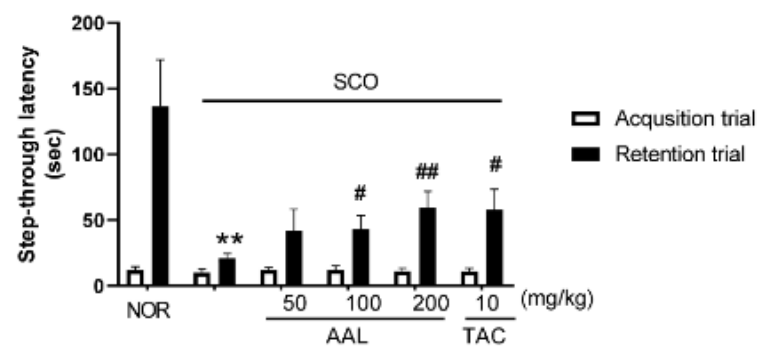

(C)

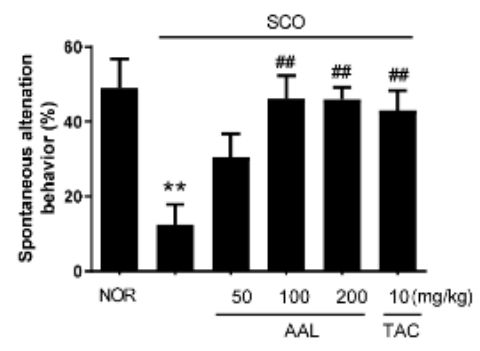

(D)

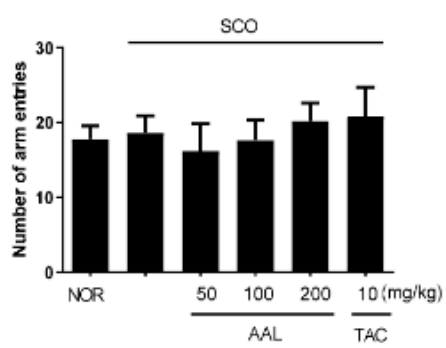

Figure 2. Effect of AAL extract on behavioral memory impairments in scopolamine-induced mice. Schematic description of the experimental timeline (A). For the passive avoidance test (PAT) (B), an acquisition trial was first performed and a retention trial was conducted for $300 \mathrm{~s}$ twenty-four hours after the acquisition trial. For the Y-maze test, the spontaneous alternation behavior (C) and the number of total arm entries were monitored during an 8-min session (D). Data are presented as the mean $\pm \mathrm{SEM}$ $(n=8) .{ }^{* *} p<0.01$ vs. NOR group, ${ }^{\#} p<0.05$ or ${ }^{\# \#} p<0.01$ vs. SCO group. NOR: normal control; SCO: scopolamine; AAL: A. atemoya leaf; TAC: tacrine.

\subsection{Effect of AAL Extract on Neuronal Cell Loss in SCO-Treated Mice}

The neuroprotective effect of AAL extract in SCO-mediated memory deficit mice was identified using cresyl violet staining in the hippocampus of mouse brains. As shown in Figure 3, the SCO group displayed marked neuronal damage and nucleus shrinkage, or staining in different shades in the Cornu 
Ammonis (CA) 1 and dentate gyrus (DG) regions of the hippocampus compared with the NOR group (Figure 3A). After treatment with AAL extract or TAC, the SCO-induced neuron damage was fairly well prevented in the hippocampus (Figure 3B,C).

(A)

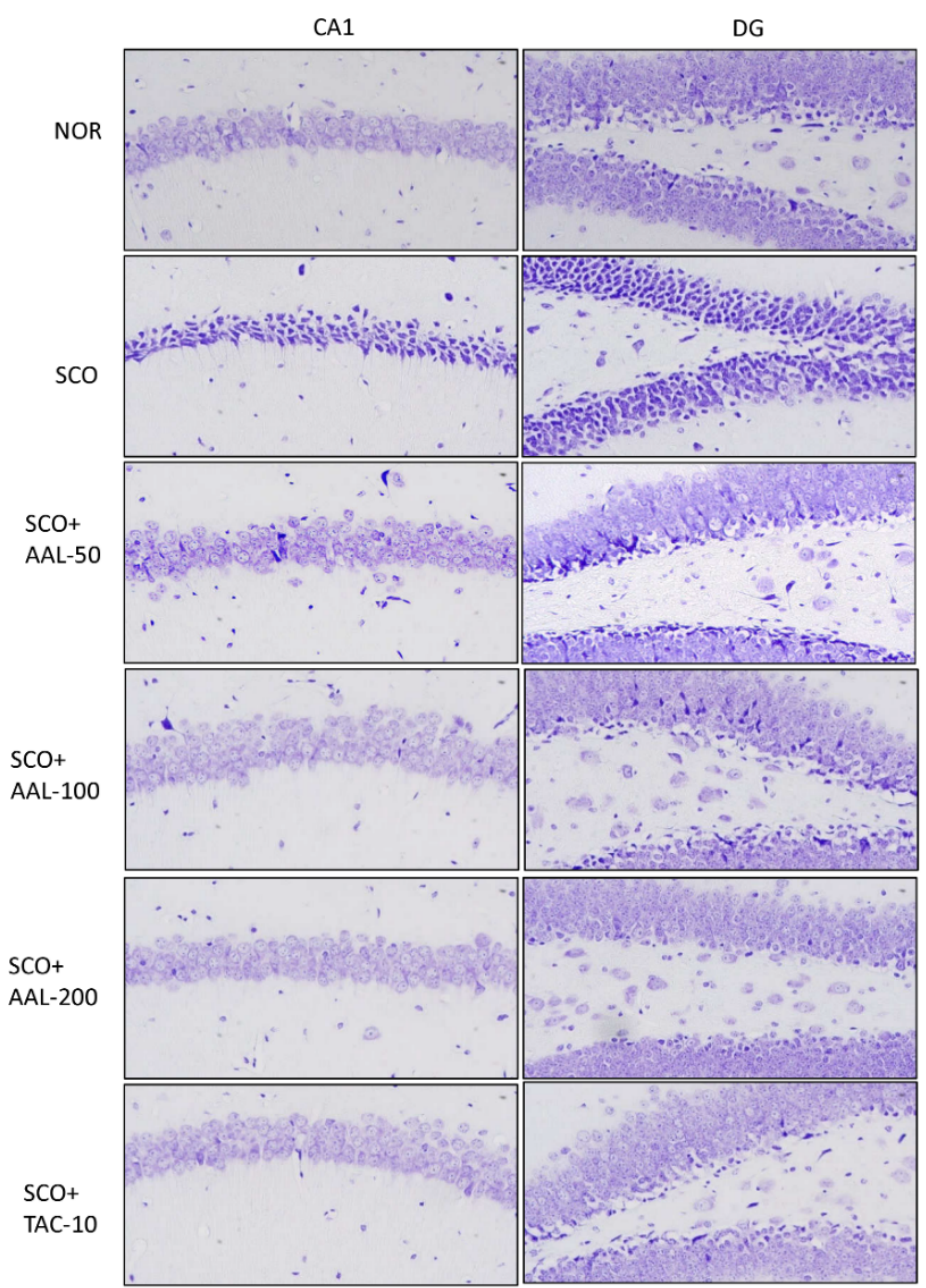

(B)
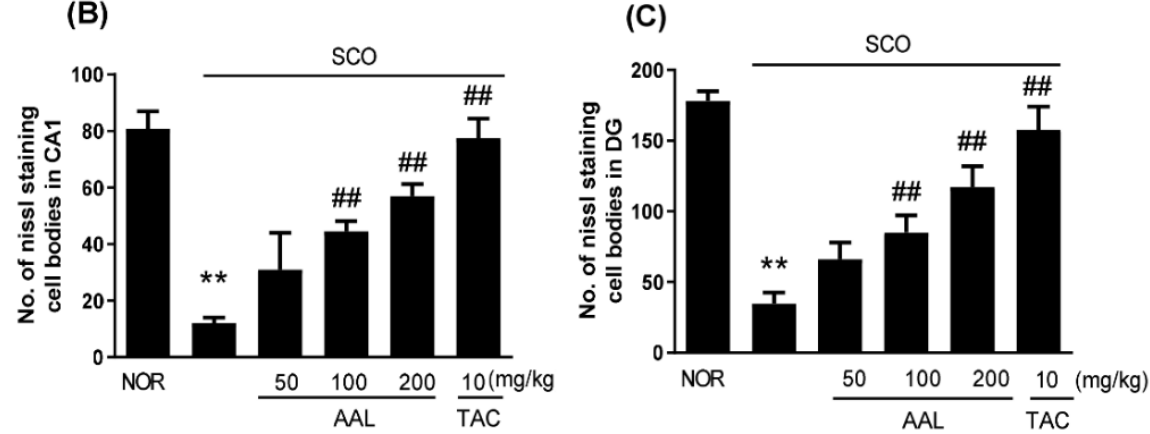

Figure 3. Effect of AAL extract on the morphological damage to neurons in scopolamine-induced cognitive deficit mouse brains. Sections of the hippocampus, including the CA1 and DG regions, were prepared for Nissl staining using cresyl violet solution. Representative photomicrographs are shown at magnifications of $\times 400$ (A). The graph shows the number (No.) of Nissl stained cells in the CA1 and the DG (B and C, respectively). CA: Cornu Ammonis; DG: dentate gyrus, Data are presented as the mean $\pm \operatorname{SEM}(n=3) .{ }^{* *} p<0.01$ vs. NOR group, ${ }^{\# \#} p<0.01$ vs. SCO group. NOR: normal control; SCO: scopolamine; AAL: A. atemoya leaf; TAC: tacrine. 


\subsection{Effect of AAL Extract on Cholinergic System and Oxidative Stress in SCO-Treated Mice}

Acetylcholine (ACh), a major excitatory neurotransmitter in neurons, is important for the formation of retention of existing memory [23]. To further elucidate the potential mechanisms of AAL extract in improving memory induced by $\mathrm{SCO}$, the levels of multifarious biochemical factors and proteins associated with the cholinergic system and oxidative stress were investigated. As shown in Figure 4, only treatment with SCO led to a remarkable decrease in ACh content and an increase in AChE activity in the hippocampus. In contrast, the AAL extract or TAC treatment group significantly reversed the effects of SCO on ACh content and AChE activity (Figure 4A,B). Consistently, the SCO group significantly decreased choline acetyltransferase (ChAT) protein expression, whereas AAL extract or TAC treatment prevented the SCO-mediated decrease in ChAT expression in the hippocampus (Figure 4C,D). Oxidative stress is related to the cognitive deficits observed in the SCO-induced cognitive deficit mouse model [24]. The SCO group exhibited significantly increased ROS levels compared with the NOR group (Figure 4E). In contrast, AAL extract treatment attenuated the SCO-induced increase in reactive oxygen species (ROS) levels in the hippocampus. The TAC group also exhibited decreased ROS levels in SCO-induced memory deficit mice. These results suggested that AAL extract could protect against $\mathrm{SCO}$-induced dysfunction of the cholinergic system and oxidative stress in brain tissue.

(A)

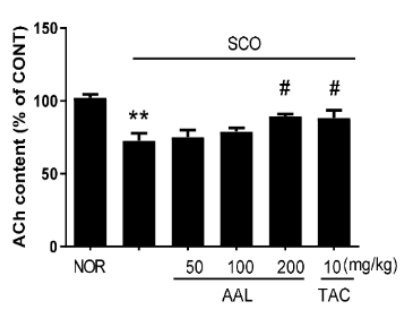

(C)

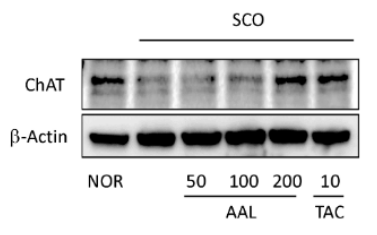

(B)

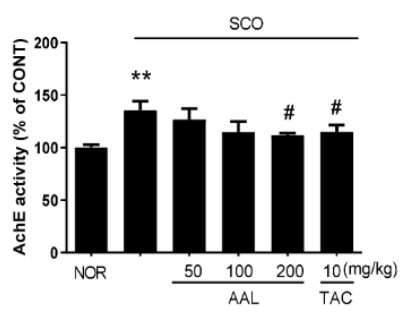

(D)

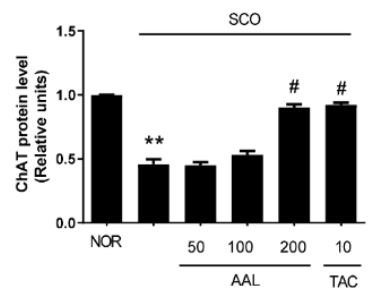

(E)

$\mathrm{SCO}$

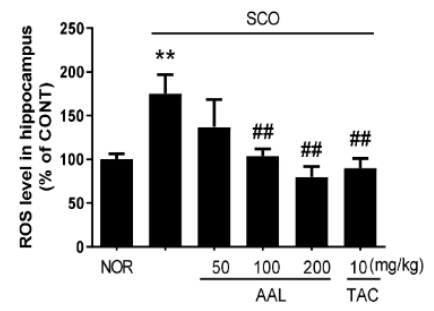

Figure 4. Effect of AAL extract on cholinergic system dysfunction and ROS production in scopolamine-induced cognitive deficit mouse brains. ACh content (A) and AChE activity (B) were measured in the hippocampus using an ACh and AChE activity assay kit (US Biomax Inc., Rockville, MD, USA). Hippocampus tissue was lysed and subjected to Western blotting with anti-ChAT antibody (C). Expression levels were normalized to $\beta$-actin. Bar graphs represent the relative band intensities 
compared with NOR (D). ROS levels in hippocampal tissue were measured using an ROS/RNS assay kit (Cell Biolabs, Inc., Sandiego, CA, USA). The fluorescence intensities corresponding to the ROS levels in the hippocampus are represented as a percentage of that in the NOR (E). Data are presented as the mean $\pm \operatorname{SEM}(n=5)$. ${ }^{* *} p<0.01$ vs. NOR group, ${ }^{\#} p<0.05$ or ${ }^{\# \#} p<0.01$ vs. SCO group. NOR: normal control; SCO: scopolamine; AAL: A. atemoya leaf; TAC: tacrine.

\subsection{Effect of AAL Extract on Apoptosis in SCO-Treated Mice}

Apoptosis has been reported to be related with mechanisms of oxidative stress and central cholinergic system dysfunction [25]. Thus, neuronal apoptosis in the hippocampus of brain tissue was determined by Western blotting and TUNEL staining. As shown in Figure 5A,B, apoptotic cells were stained purple in the hippocampal region in the SCO group. AAL extract or TAC treatment resulted in a dramatic decrease in the number of apoptotic cells in the hippocampal region compared with the number observed in the SCO group. The relative protein levels of cleaved caspase- 3 and Bax were increased in the SCO group compared with the NOR group. The relative protein level of $\mathrm{Bcl} 2$ was lower in the SCO group than in the NOR group. In contrast, the AAL extract and TAC groups exhibited significant preventative effects on apoptotic activation in the SCO-induced cognitive deficit mouse brain. These results suggest that treatment with AAL extract markedly attenuated apoptosis in the hippocampus region of SCO-induced cognitive deficit mice (Figure 5C).

(A)
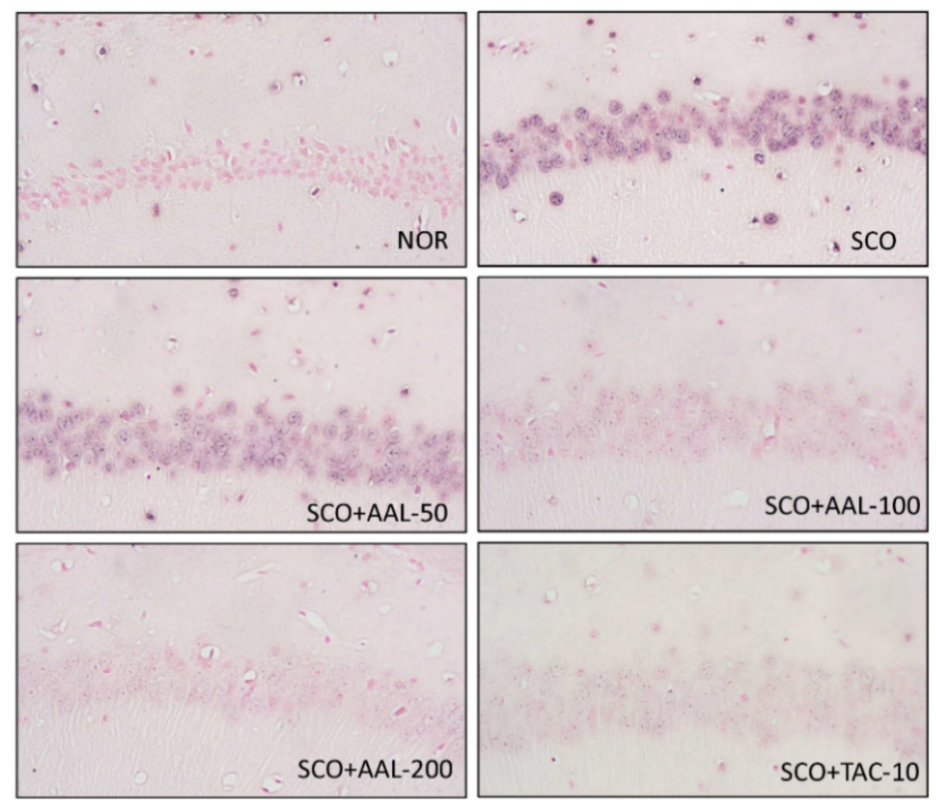

(B)

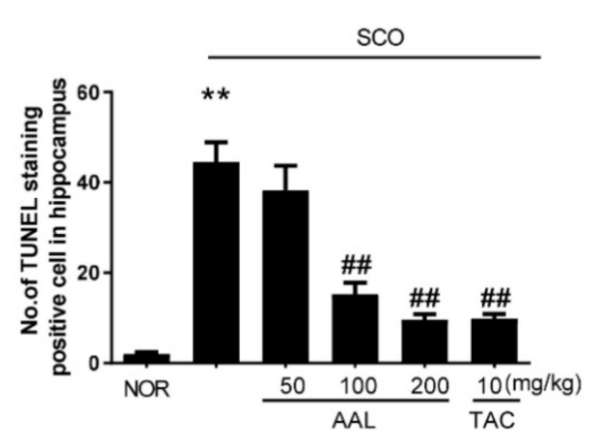

(C)

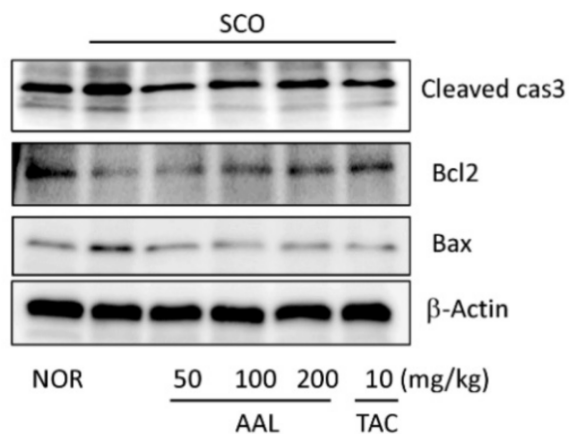

Figure 5. Effect of AAL extract on the expression of apoptosis-related proteins in scopolamine-induced cognitive deficit mouse brains. Representative photomicrographs were taken at magnifications of $\times 400$ (A). Apoptotic cells 
were visualized with nitroblue tetrazolium and 5-bromo-4-chloro-3-indolylphosphate (NBT/BCIP-AP, purple). Counterstaining for nuclei was performed with Fast-red. Bar graphs represent a quantitative analysis of the apoptotic signals in histological sections of the hippocampus (B). Data are presented as the mean $\pm \operatorname{SEM}(n=3)$. ${ }^{* *} p<0.01$ vs. NOR group, ${ }^{\# \#} p<0.01$ vs. SCO group. Hippocampal tissues were lysed and subjected to Western blotting with anti-Bax, Bcl 2 and cleaved caspase- 3 antibodies (C). Expression levels were normalized to $\beta$-actin. NOR: normal control; SCO: scopolamine; AAL: A. atemoya leaf; TAC: tacrine.

2.6. Effect of AAL Extract on SCO-Attenuated Expression of BDNF and Phosphorylation of CREB and Akt in the Hippocampus

Brain Derived Neurotrophic Factor (BDNF) and phosphorylated cAMP response element binding protein (pCREB) are critical factors associated with learning and memory formation, and activation of CREB transcriptional activity regulates BDNF expression to induce learning and memory function [26]. The effects of AAL extract on the expression of BDNF and phosphorylation of CREB in mouse brain tissues were examined by immunohistochemistry and Western blot analysis. As shown in Figure $6 \mathrm{~A}, \mathrm{~B}$, the SCO group showed the reduced pCREB and BDNF levels in the hippocampus. Meanwhile, AAL extract treatment markedly prevented the SCO-induced decrease in PCREB and BDNF levels $(p<0.01)$. We also examined Akt activation to investigate the potential mechanisms by which AAL extract may promote hippocampal neurogenesis and protect against SCO-induced memory deficits. Our results showed that AAL extract protected against SCO-mediated Akt inactivation in hippocampal tissues (Figure 6C). These results suggest that AAL extract may promote memory function through a mechanisms associated with the activation of neurogenic factors BDNF/CREB and survival protein Akt in the SCO-induced memory deficit mouse model.

(A)

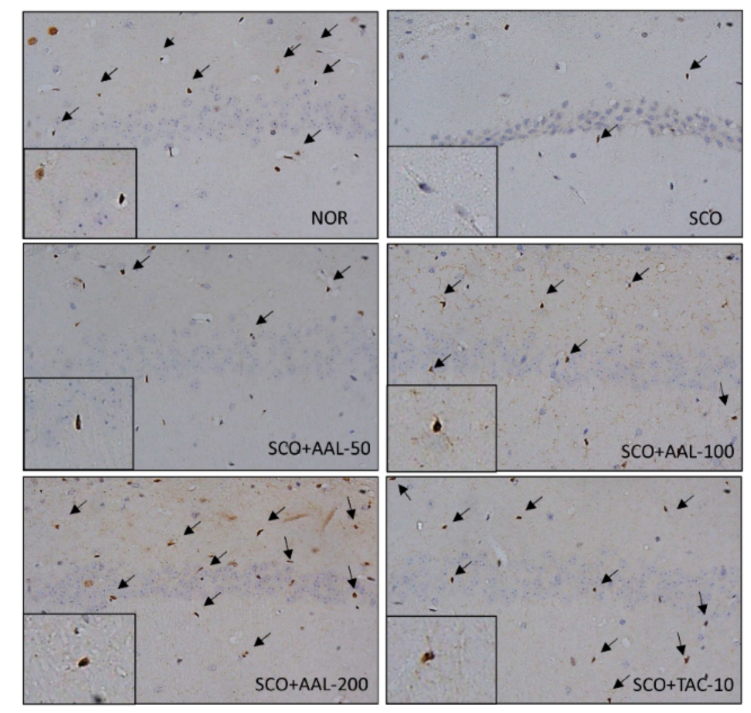

Figure 6. Cont. 
(B)

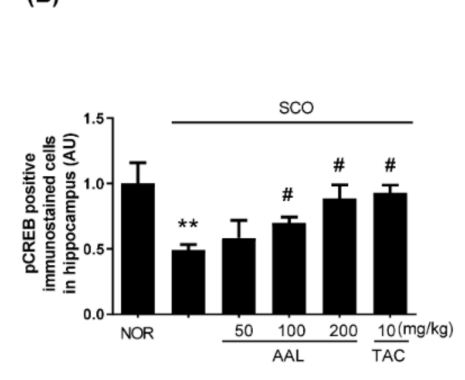

(C)

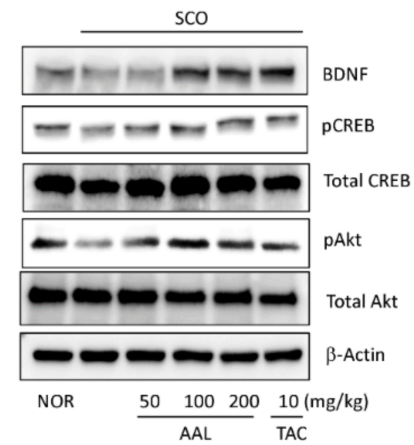

Figure 6. Effect of AAL extract on the levels of hippocampal BDNF, pCREB, and pAkt proteins in scopolamine-induced cognitive deficit mouse brains. Representative images show DAB immunostaining for phospho-CREB (pCREB) in the hippocampal region (A). The immunostained positive cells were calculated in brain tissue sections from each mouse (B). The graphs show the number of pCREB-positive cells in the hippocampal region. Data are presented as the mean $\pm \operatorname{SEM}(n=3) .{ }^{* *} p<0.01 \mathrm{vs}$. NOR group, ${ }^{\#} p<0.05$ vs. SCO group. Hippocampus tissues were lysed and subjected to Western blotting with anti-BDNF, phospho-CREB, total CREB, phospho-Akt, and total Akt antibodies (C). The protein levels were normalized to total CREB, total Akt, and $\beta$-actin, respectively. NOR: normal control; SCO: scopolamine; AAL: A. atemoya leaf; TAC: tacrine.

\section{Discussion}

Cumulative evidence has suggested that cognitive dysfunction in $\mathrm{AD}$ is the result of impaired neurogenesis in the hippocampus of the adult brain, and it is crucial to identify novel drugs that can be used for the treatment of $\operatorname{AD}[27,28]$. The cholinergic function is reduced in the forebrain, especially in the hippocampus, and a change in AChE activity in the hippocampus is usually a biomarker for diagnosing AD [29]. SCO impairs memory in rodents and humans, which interferes with the cholinergic system, including $\mathrm{ACh}$, and causes oxidative stress, leading to cognitive dysfunction [30-32]. Thus, SCO-induced cognitive impairment is a valid model to investigate the anti-AD effects of novel drugs. In the present study, we investigated the effects of AAL extract in a SCO-induced memory deficit mouse model. The results showed that AAL extract treatment significantly improved memory dysfunction by ameliorating cholinergic system impairment and oxidative stress in SCO-induced cognitive deficit mice. In addition, AAL extract could have a neuroprotective effect against $\mathrm{SCO}$-induced apoptosis in the hippocampus.

$\mathrm{AD}$ is highly related to cholinergic system impairment and intracellular oxidative stress [7,29]. Hippocampal cholinergic dysfunction has been identified in neurodegenerative diseases that are characterized by memory impairment, including AD, and in animal experiments [33,34]. Previous studies reported that mice receiving SCO alone showed a marked decrease in the cholinergic system reactivity, as indicated by decreased ACh level and increased AChE activity along with decreased ChAT activity, resulting in cognitive deficiency and neuronal cell death in the hippocampus $[35,36]$. It has been established that SCO induces memory impairment associated with dysfunction of cholinergic neurotransmission as well as increases processes connected with oxidative stress in the brain [37]. An imbalance between ROS production and antioxidant capacity is associated with numerous diseases, including neurodegenerative diseases [38]. ROS play a critical role in neuron loss and can cause extensive damage to proteins and DNA, leading to changes in the structures and functions of neural cells in the brain [39]. Apoptosis is considered to be one of the main causes of neurodegeneration, and ROS can directly lead to apoptosis responses. Of the caspase family, caspase- 3 is the terminal executing enzyme in apoptosis. Caspase-3 can disrupt the structural protein of cells and lead to apoptosis. In contrast to the antiapoptotic protein $\mathrm{Bcl} 2$, the proapoptotic Bax protein is associated with the activation of apoptosis [40]. Thus, protective effects against apoptosis and oxidative damage in neurodegenerative diseases are important factors to consider in the discovery of new therapeutic drugs. 
In the present study, we used the Y-maze test and PAT to measure memory deficits in SCO-treated mice. The results showed that AAL extract treatment significantly improved spontaneous alternation in the Y-maze test and the step-through latency in the retention trial of the PAT in SCO-induced cognitive deficit mice. TAC (positive control) could also effectively ameliorate these changes in SCO-induced cognitive deficit mice and improve their learning and memory. Moreover, AAL extract effectively attenuated the SCO-induced dysfunction of the cholinergic system and neuronal cell damage in the hippocampus in the brain, corresponding to a preventative effect against memory impairment. We found that AAL extract dramatically increased the scavenging rates against ABTS and DPPH radicals, indicating antioxidant activity of AAL (data not shown, unpublished data). In addition, this study showed that AAL extract significantly reduced ROS production in hippocampal tissues of SCO-induced cognitive deficit mice. TUNEL staining also demonstrated that AAL extract significantly ameliorated neuronal apoptosis, including a reduction in cleaved caspase- 3 and Bax protein expression in the hippocampus of SCO-induced cognitive deficit mice. These results suggested that the protective effect of AAL extract against SCO-induced memory deficit is related to inhibit the damage caused by ROS and the subsequent apoptosis. Therefore, in this study suggests that AAL extract might ameliorate memory impairment through the anticholinergic system and by preventing oxidative stress and neuronal cell apoptosis.

Many studies have shown that the signaling pathways involving BDNF/pCREB and Akt play crucial roles in the modulation of hippocampal neurogenesis in memory-impaired rodent models and in patients with dementia [41-43]. Activation of CREB transcriptional activity regulates BDNF expression to induce cognitive function. BDNF overexpression increases Akt activation and stimulates pCREB in neuroprotection against brain pathology $[44,45]$. In agreement with these findings, we confirmed that SCO treatment markedly decreased the expression of BDNF, and levels of pCREB and pAkt by Western blot analysis. Consistently, SCO administration decreased the number of pCREB-positive cells in the hippocampal region by immunostaining. In contrast, treatment with AAL extract effectively prevented these SCO-induced reductions in BDNF/pCREB and pAkt. These findings indicate that AAL exerts memory-enhancing effects through regulation of the BDNF/pCREB and Akt pathways.

HPLC analysis confirmed that AAL has two major components rutin and isoquercitrin, which constitute 16.65 and $2.09 \mathrm{mg} / \mathrm{g}$, respectively. In previous studies, rutin showed potential neuroprotective effects against cerebral injury induced by ischemic reperfusion by ameliorating neurological impairments and oxidative damage [46,47]. Moreover, rutin alleviated AD-type streptozotocin-induced neurodegeneration and the associated cognitive impairment in a working memory animal model [48]. Rutin has the potential to prevent short- and long-term memory deficits; the use of rutin would contribute to increase plant-derived products for use as medicines to treat neurodegenerative diseases. Isoquercitrin is one of the main flavonoid glycosides and has been reported to have beneficial effects against oxidative stress, diabetes, and cancer and act as an anti-inflammatory agent [49-52].

Ip PS et al. recently suggested that complementary and alternative medicines could be potential sources of new drugs for the prevention of neurodegenerative diseases [53]. Earlier reports revealed that dietary intake of rich polyphenolic vegetables and fruits delayed the onset of dementia associated with AD [54,55]. Although $N$-methyl D-aspartate receptor antagonists and cholinesterase inhibitors have been widely used for treating the symptoms of $\mathrm{AD}$, these drugs have not shown promising results, and their usage is limited due to their undesirable side effects. In connection with the above-described reports, AAL extract could be a promising and effective treatment against neurodegenerative diseases, including AD. 


\section{Materials and Methods}

\subsection{Preparation of Ethanol Extract from $A A L$}

AAL was provided by Sunny Farm (Jeju, South Korea). Dried AAL $(2.7 \mathrm{~kg})$ was extracted twice with $60 \mathrm{~L}$ ethanol using an electric extractor (COSMOS-660, Kyungseo Machine Co., Incheon, Korea) for $3 \mathrm{~h}$ each time. The filtered extract solution was evaporated and freeze-dried to yield $868.03 \mathrm{~g}$ (yield $=32.15 \%$ ) of powdered extracts. A sample specimen (SCD-A-111) was kept at the Clinical Medicine Division, Korea Institute of Oriental Medicine.

\subsection{Reagents and Chemicals}

Rutin and isoquercitrin, as standard components, were obtained from ChemFaces Biochemical Co., Ltd. (Wuhan, China), and these standard components were purified to $\geq 98.0 \%$ by high-performance liquid chromatography (HPLC) analysis. The HPLC-grade water and acetonitrile were obtained from J. T. Baker Chemical Co. (Phillipsburg, NJ, USA), and the trifluoroacetic acid (TFA) was obtained from Sigma-Aldrich (St. Louis, MO, USA).

\subsection{Preparation of Sample and Standard Solutions for HPLC Analysis}

The powdered AAL extract was weighed at $10 \mathrm{mg} / \mathrm{mL}$ and dissolved in $90 \%$ aqueous methanol. The sample solution was passed through a syringe filter $(0.45 \mu \mathrm{m})$ for HPLC analysis. To make standard solutions of the two compounds, each compound was weighed accurately and dissolved at a concentration of $1.0 \mathrm{mg} / \mathrm{mL}$ in methanol, and these stock solutions were mixed and diluted before HPLC analysis.

\subsection{Chromatographic Conditions}

HPLC analysis was used Waters Alliance e2695 HPLC system (Waters Corp., Milford, MA, USA) equipped with a pump, degasser, column oven, automatic sample injector, and photodiode array (PDA) detector (\#2998; Waters Corp.). Chromatographic separation for the two standard compounds was carried out with a Luna C18 analytical column $(250 \times 4.6 \mathrm{~mm}, 5 \mu \mathrm{m}$, Phenomenex, Torrance, CA, USA) maintained at $40{ }^{\circ} \mathrm{C}$. The mobile phases consisted of $0.1 \%(v / v)$ aqueous TFA (A) and acetonitrile (B). The gradient conditions were as follows; $10 \%$ B for $0-10 \mathrm{~min}, 10-30 \%$ B for $10-40 \mathrm{~min}$, and $100 \%$ B for $40-50 \mathrm{~min}$. The flow rate was $1.0 \mathrm{~mL} / \mathrm{min}$, and the injection volume was $10 \mu \mathrm{L}$. The data were acquired and processed using Empower software (version 3; Waters Corp).

\subsection{Animal and Drug Treatments}

The experiments were performed according to the National Institutes of Health (NIH) Guide for the Care and Use of Laboratory Animals and approved by the Korea Institute of Oriental Medicine Institutional Animal Care and Use Committee (IACUC Approval No.17-044, Approval date 29, March, 2017). Seven-week-old male ICR mice were purchased from the Daehan Biolink (Cheongju, Korea) and acclimated for 1 week prior to the study with standard food and water supplied ad libitum in individual acryl cages. All mice were housed under controlled conditions (12 h light/dark cycle; temperature: $22 \pm 2{ }^{\circ} \mathrm{C} ; 55 \%$ humidity). The study began when the ICR mice were 8 weeks old (weight: $\sim 35 \mathrm{~g}$ ), and the mice were monitored for 3 weeks. Memory deficit was induced by a single injection of SCO $(1 \mathrm{mg} / \mathrm{kg}$, i.p.). Age-matched control mice received an equal volume of vehicle (phosphate buffered saline, PBS). Fifty-eight male ICR mice were randomly divided to one of 6 groups $(n=8)$. AAL extract was dissolved in distilled water (DW) to concentrations of 50,100 , and $200 \mathrm{mg} / \mathrm{kg}$ and administered daily by gastric gavage; the other groups were given TAC (USP, Rockville, MD, USA) as a positive control $(10 \mathrm{mg} / \mathrm{kg}$ ). All mice underwent behavioral tests from the 15th to the 20th day. All mice were injected with SCO within 60 min after oral administration of AAL extract or TAC solution except for mice in the normal control group, which received saline 
(i.p.) $30 \mathrm{~min}$ after treatment with PBS. The behavioral tests were conducted $30 \mathrm{~min}$ after SCO injection. All efforts were made to minimize animal suffering. The animal equivalent dosage was determined from the human equivalent dose. We considered that the usual dosage of the plant is approximately $20-80 \mathrm{~g} / 70 \mathrm{~kg} / \mathrm{day}$ of the raw plant for adult human. The calculated animal dose range was from 40 to $250 \mathrm{mg} / \mathrm{kg}$ in mice. The AAL dose for this study was determined 50, 100, or $200 \mathrm{mg} / \mathrm{kg}$ per day. Animal experiments were performed under nontoxic concentration of AAL. This animal study procedures were performed according to ARRIVE guideline.

\subsection{Brain Section and Tissue Preparation}

All mice were sacrificed under anesthesia at the end of the experimental period and the hippocampal and cortex tissues were immediately isolated on ice and stored at $-80{ }^{\circ} \mathrm{C}$ for further analysis. Three mouse brains from each group were perfused intracardially with PBS (pH 7.4) and fixed in 4\% paraformaldehyde.

\subsection{Western Blot Analysis}

Hippocampal and cortical brain tissues were homogenized in RIPA buffer ( $\mathrm{pH}$ 7.5) with phosphatase and protease inhibitors (Pierce Biotechnology, Rockford, IL, USA). The proteins were separated on $4-20 \%$ gradient polyacrylamide gels and then transferred on PVDF membranes. Blocked PVDF membranes with $5 \%$ nonfat milk were washed with TBST solution for nonspecific binding. The blocked membranes were incubated with rabbit anti-total CREB, pCREB, ChAT, total Akt, pAkt, cleaved caspase-3, Bax, Bcl2 (Cell Signaling Technology, Danvers, MA, USA, 1:2000 dilution), and mouse anti-ß-actin (Santa Cruz Biotechnology Inc., Dallas, TX, USA, 1:3000 dilution). Washed membranes were incubated with secondary antibodies with conjugated horseradish peroxidase and immunoblot bands were developed using supersignal ECL solution (Amersham Bioscience, Piscataway, NJ, USA). Protein levels were detected by analyzing the captured signals using a ChemiDox imaging analyzer (Las-4000 MINI, Fuji photo, Tokyo, Japan).

\subsection{Measurement of ACh Level and AChE Activity Assay}

ACh levels and $\mathrm{AChE}$ activity in hippocampal and cortical tissues were measured using respective assay kits (US Biomax Inc, Denwood, MD, USA) in accordance with the manufacturer's protocol. Absorbance of mixture was measured at $570 \mathrm{~nm}$ using a spectrophotometer (Benchmark Plus, Bio-Rad, Hercules, CA, USA).

\subsection{Nissl and TUNEL Staining}

After 3 weeks of AAL extract treatment, fixed brain tissues with $4 \%$ paraformaldehyde were embedded in paraffin, and $4-\mu \mathrm{m}$-thick sections were prepared. Staining was performed as previously described [56]. Deparaffinized and hydrated slides were dipped in 1\% Nissl stain solution (cresyl violet) for 1 min and washed with tap water. TUNEL staining was performed with an in situ cell death detection AP kit (Roche Diagnostics, Mannheim, Germany) according to the manual's instruction. Apoptotic cells were stained with a color solution containing nitroblue tetrazolium and 5-bromo-4-chloro-3-indolylphosphate (NBT/BCIP, Roche Diagnostics). Stained sections were then visualized using an Olympus DP71 (Tokyo, Japan) at 400 magnification. The images were analyzed using ImageJ software (Java-based image processing program, $\mathrm{NIH}$ ).

\subsection{Passive Avoidance Test (PAT)}

The PAT, conducted using two identical compartments (Electronic shock generator, Jeungdo Bio \& Plant Co. Ltd., Seoul, Korea) consisted of lighted and darkened compartment with a door in between compartments and electrifiable grid floor. During the acquisition phase, mice were placed in the lighted compartment for familiarization for $25 \mathrm{~s}$ and then crossed to the darkened compartment. The door 
was opened and then received a mild electrical shock $(0.3 \mathrm{~mA}, 3 \mathrm{~s})$. In retention phase, mice were again placed in the lighted compartment. The latency time of the darkened compartment required the mice to remain in lighted compartment was recorded as the retention time. If the mice did not enter the darkened compartment within $5 \mathrm{~min}$, the latency time was recorded as $300 \mathrm{~s}$. No physiological defects (i.e., motor deficits) or intrinsic cognitive impairments were observed in any of the mouse groups prior to treatment with SCO.

\subsection{Y-Maze Test}

The Y-maze (length: $35 \mathrm{~cm}$; height: $15 \mathrm{~cm}$; width: $7 \mathrm{~cm}$ ) tests were positioned at equal angles three arms from one another. Each mouse was placed in one arm and allowed to freely explore the maze for $8 \mathrm{~min}$. The number of spontaneous alternations was recorded using a tracking system (EthoVision XT, Noldus Information Tech, Wageningen, The Netherlands). Spontaneous alternation (\%) was considered when mice entered into all three arms without repetition and the rate of spontaneous alternation was as follows; \% alternation $=[($ number of alternations $) /($ total number of arm entries- 2$)] \times 100$.

\subsection{Measurement of Reactive Oxygen Species (ROS) in Hippocampus}

The total free radical presence in the homogenized hippocampus brain tissues was determined using an ROS/reactive nitrogen species (RNS) free radical activity assay kit (Cell Biolabs, Inc., San Diego, CA, USA) according to the manufacturer's protocol. Fifty microliters of sample solution, hydrogen peroxide solution, or 2', $7^{\prime}$-dichlorodihydrofluorescein (DCF) solution was added to each well of a 96-well plate, and $50 \mu \mathrm{L}$ of catalyst was added to each well, followed by incubation for $5 \mathrm{~min}$ at room temperature. Then, $100 \mu \mathrm{L}$ of prepared dichlorodihydrofluorescin (DCFH) solution was added to each well. The plate was covered and incubated at room temperature for $45 \mathrm{~min}$. The fluorescence intensity of the resulting solution was measured at $480 / 530 \mathrm{~nm}$ excitation and emission with a SpectraMax multimode detection platform fluorometer (Molecular Devices, Sunnyvale, CA, USA).

\subsection{Statistical Analysis}

All data were expressed as the mean \pm SEM and statistical analyses were evaluated via a one-way analysis of variance (ANOVA) followed by an unpaired Student's $t$-test or Tukey's multiple comparison test. All experiments were performed individually at least three times. GraphPad Prism 8.0 software program (Graph pad, San Diego, CA, USA) was used for all analyses. Difference at $p<0.05$ was considered to be statistical significance.

\section{Conclusions}

The effects of AAL on improving memory loss resulted from ameliorating cholinergic system dysfunction, which could lead to the progression of neurodegenerative disorders, and preventing apoptotic activity, which would otherwise promote neuronal damage due to oxidative stress in the brain. Moreover, AAL extract treatment exerted memory-enhancing effects via inhibition of the BDNF/pCREB and Akt signaling pathways in SCO-induced cognitive deficit mice. Taken together, our findings suggest that AAL extract—a natural product—could be potentially used to develop a novel drug for the treatment of $\mathrm{AD}$.

Author Contributions: E.S. and S.-J.J. designed the study, analyzed the data, and prepared the manuscript. E.S., H.-S.L., Y.J.K., and B.-Y.K. executed the biological examination of experiments. Y.J.K. prepared and analyzed the AAL extract. All authors reviewed the manuscript and approved the final manuscript.

Funding: This research was funded by the Korea Institute of Oriental Medicine (KIOM), grant number KSN1515293.

Conflicts of Interest: The authors declare no conflicts of interest. The funders had no role in the design of the study; in the collection, analyses, or interpretation of data; in the writing of the manuscript, or in the decision to publish the results. 


\section{Abbreviations}

$\begin{array}{ll}\text { ACh } & \text { Acetylcholine } \\ \text { AChE } & \text { Acetylcholinesterase } \\ \text { pAkt } & \text { Phophorylated protein kinase B (Akt) } \\ \text { PBS } & \text { Phosphate-buffered saline } \\ \text { Bcl2 } & \text { B-cell lymphoma } 2 \\ \text { Bax } & \text { Bcl2-associated X protein } \\ \text { pCREB } & \text { Phosphorylated cAMP response elements binding protein } \\ \text { BDNF } & \text { Brain derived neurotrophic factor } \\ \text { ChAT } & \text { choline acetyltransferase } \\ \text { HPLC } & \text { High-performance liquid chromatography } \\ \text { TFA } & \text { Trifluoroacetic acid } \\ \text { ABTS } & \text { 2,2'-azino-bis (3-ethylbenzothiazoline-6-sulfonic acid) } \\ \text { DPPH } & \text { 2,2diphenyl-1-picrylhydrazyl } \\ \text { DCFH } & \text { dichlorodihydrofluorescin } \\ \text { DCF } & \text { 2', } 7^{\prime} \text {-dichlorodihydrofluorescein } \\ \text { RIPA } & \text { Radioimmunoprecipitation assay buffer } \\ \text { ROS } & \text { reactive oxygen species } \\ \text { TUNEL } & \text { Terminal deoxynucleotidyl transferase dUTP nick end labeling }\end{array}$

\section{References}

1. Bartus, R.T.; Dean, R.L., 3rd. Pharmaceutical treatment for cognitive deficits in Alzheimer's disease and other neurodegenerative conditions: exploring new territory using traditional tools and established maps. Psychopharmacology 2009, 202, 15-36. [CrossRef] [PubMed]

2. Lazarov, O.; Mattson, M.P.; Peterson, D.A.; Pimplikar, S.W.; van Praag, H. When neurogenesis encounters aging and disease. Trends Neurosci. 2010, 33, 569-579. [CrossRef] [PubMed]

3. Lim, H.S.; Kim, Y.J.; Sohn, E.; Yoon, J.; Kim, B.Y.; Jeong, S.J. Bojungikgi-Tang, a Traditional Herbal Formula, Exerts Neuroprotective Effects and Ameliorates Memory Impairments in Alzheimer's Disease-Like Experimental Models. Nutrients 2018, 10, 1952. [CrossRef] [PubMed]

4. Scheff, S.W.; Price, D.A.; Schmitt, F.A.; Mufson, E.J. Hippocampal synaptic loss in early Alzheimer's disease and mild cognitive impairment. Neurobiol. Aging 2006, 27, 1372-1384. [CrossRef] [PubMed]

5. Lu, C.; Wang, Y.; Xu, T.; Li, Q.; Wang, D.; Zhang, L.; Fan, B.; Wang, F.; Liu, X. Genistein ameliorates scopolamine-Induced amnesia in mice through the regulation of the cholinergic neurotransmission, antioxidant system and the ERK/CREB/BDNF signaling. Front. Pharmacol. 2018, 9, 1153. [CrossRef] [PubMed]

6. Araujo, J.A.; Studzinski, C.M.; Milgram, N.W. Further evidence for the cholinergic hypothesis of aging and dementia from the canine model of aging. Prog. Neuropsychopharmacol. Biol. Psychiatry 2005, 29, 411-422. [CrossRef]

7. Niedzielska, E.; Smaga, I.; Gawlik, M.; Moniczewski, A.; Stankowicz, P.; Pera, J.; Filip, M. Oxidative stress in neurodegenerative diseases. Mol. Neurobiol. 2016, 53, 4094-4125. [CrossRef]

8. Terry, A.V., Jr.; Buccafusco, J.J. The cholinergic hypothesis of age and Alzheimer's disease-related cognitive deficits: recent challenges and their implications for novel drug development. J. Pharmacol. Exp. Ther. 2003, 306, 821-827. [CrossRef]

9. Zhou, X.; Li, Y.; Shi, X.; Ma, C. An overview on therapeutics attenuating amyloid beta level in Alzheimer's disease: Targeting neurotransmission, inflammation, oxidative stress and enhanced cholesterol levels. Am. J. Transl. Res. 2016, 8, 246-269.

10. Lu, C.; Dong, L.; Lv, J.; Wang, Y.; Fan, B.; Wang, F.; Liu, X. 20(S)-protopanaxadiol (PPD) alleviates scopolamine-induced memory impairment via regulation of cholinergic and antioxidant systems, and expression of Egr-1, c-Fos and c-Jun in mice. Chem. Biol. Interact. 2018, 279, 64-72. [CrossRef]

11. Jeon, S.J.; Kim, B.; Park, H.J.; Zhang, J.; Kwon, Y.; Kim, D.H.; Ryu, J.H. The ameliorating effect of 1-palmitoyl-2-linoleoyl-3-acetylglycerol on scopolamine-induced memory impairment via acetylcholinesterase inhibition and LTP activation. Behav. Brain Res. 2017, 324, 58-65. [CrossRef] 
12. De Cássia Seffrin, R.; Shikano, I.; Akhtar, Y.; Isman, M.B. Effects of crude seed extracts of Annona atemoya and Annona squamosa L. against the cabbage looper, Trichoplusia ni in the laboratory and greenhouse. Crop Prot. 2010, 29, 20-24. [CrossRef]

13. Wongs-Aree, C.; Noichinda, S. Sugar apple (Annona squamosa L.) and atemoya (A. cherimola Mill. $\times$ A. squamosa L.). In Postharvest Biology and Technology of Tropical and Subtropical Fruits; Woodhead Publishing: Cambridge, UK, 2011; Volume 4, pp. 399-426.

14. Dutra, L.M.; Costa, E.V.; Moraes, V.R.; Nogueira, P.C.; Vendramin, M.E.; Barison, A.; Prata, A.P. Chemical constituents from the leaves of Annona pickelii (Annonaceae). Biochem. Syst. Ecol. 2012, 41, 115-118. [CrossRef]

15. Leboeuf, M.; Cavé, A.; Bhaumik, P.K.; Mukherjee, B.; Mukherjee, R. The phytochemistry of the annonaceae. Phytochemistry 1980, 21, 2783-2813. [CrossRef]

16. Paull, R.E. Tropical Fruits. Crop Product. Sci. Hortic. 2011, 1, 148-150.

17. Brandão, A.E. National Composition of Fruit Cultivars; Academic Press: Waltham, MA, USA, 2016.

18. Chih, H.W.; Chiu, H.F.; Tang, K.S.; Chang, F.R.; Wu, Y.C. Bullatacin, a potent antitumor annonaceous acetogenin, inhibits proliferation of human hepatocarcinoma cell line 2.2 .15 by apoptosis induction. Life Sci. 2001, 69, 1321-1331. [CrossRef]

19. Chiu, H.F.; Chih, T.T.; Hsian, Y.M.; Tseng, C.H.; Wu, M.J.; Wu, Y.C. Bullatacin, a potent antitumor Annonaceous acetogenin, induces apoptosis through a reduction of intracellular cAMP and cGMP levels in human hepatoma 2.2.15 cells. Biochem. Pharmacol. 2003, 65, 319-327. [CrossRef]

20. Yi, J.M.; Park, J.S.; Lee, J.; Hong, J.T.; Bang, O.S.; Kim, N.S. Anti-angiogenic potential of an ethanol extract of Annona atemoya seeds in vitro and in vivo. BMC Complement Altern. Med. 2014, 14, 353. [CrossRef]

21. Rabêlo, S.V.; Costa, E.V.; Barison, A.; Dutra, L.M.; Nunes, X.P.; Tomaz, J.C.; Almeida, J.R. Antioxidant and antimicrobial activity of extracts from Atemoya. Rev. Bras. Frutic. 2014, 36, 265-271. [CrossRef]

22. Rabêlo, S.V.; Costa, E.V.; Barison, A.; Dutra, L.M.; Nunes, X.P.; Tomaz, J.C.; Almeida, J.R. Alkaloids isolated from the leaves of atemoya (Annona cherimola Annona squamosa). Braz. J. Pharmagn. 2015, 25, 419-421. [CrossRef]

23. Anand, P.; Singh, B. A review on cholinesterase inhibitors for Alzheimer's disease. Arch. Pharm. Res. 2013, 36, 375-399. [CrossRef] [PubMed]

24. Shi, J.; Liu, Q.; Wang, Y.; Luo, G. Coadministration of huperzine A and ligustrazine phosphate effectively reverses scopolamine-induced amnesia in rats. Pharmacol. Biochem. Behav. 2010, 96, 449-453. [CrossRef] [PubMed]

25. Hou, X.Q.; Wu, D.W.; Zhang, C.X.; Yan, R.; Yang, C.; Rong, C.P.; Zhang, L.; Chang, X.; Su, R.Y.; Zhang, S.J.; et al. BushenYizhi formula ameliorates cognition deficits and attenuates oxidative stressrelated neuronal apoptosis in scopolamineinduced senescence in mice. Int. J. Mol. Med. 2014, 34, 429-439. [CrossRef] [PubMed]

26. Scott Bitner, R. Cyclic AMP response element-binding protein (CREB) phosphorylation: a mechanistic marker in the development of memory enhancing Alzheimer's disease therapeutics. Biochem. Pharmacol. 2012, 83, 705-714. [CrossRef] [PubMed]

27. Kouemou, N.E.; Taiwe, G.S.; Moto, F.C.O.; Pale, S.; Ngoupaye, G.T.; Njapdounke, J.S.K.; Nkantchoua, G.C.N.; Pahaye, D.B.; Bum, E.N. Nootropic and Neuroprotective Effects of Dichrocephala integrifolia on scopolamine mouse model of Alzheimer's Disease. Front. Pharmacol. 2017, 8, 847. [CrossRef]

28. Li, S.P.; Wang, Y.W.; Qi, S.L.; Zhang, Y.P.; Deng, G.; Ding, W.Z.; Ma, C.; Lin, Q.Y.; Guan, H.D.; Liu, W.; et al. Analogous beta-Carboline Alkaloids Harmaline and Harmine Ameliorate Scopolamine-Induced Cognition Dysfunction by Attenuating Acetylcholinesterase Activity, Oxidative Stress, and Inflammation in Mice. Front. Pharmacol. 2018, 9, 346. [CrossRef]

29. Orta-Salazar, E.; Cuellar-Lemus, C.A.; Diaz-Cintra, S.; Feria-Velasco, A.I. Cholinergic markers in the cortex and hippocampus of some animal species and their correlation to Alzheimer's disease. Neurologia 2014, 29, 497-503. [CrossRef]

30. Rahnama, S.; Rabiei, Z.; Alibabaei, Z.; Mokhtari, S.; Rafieian-Kopaei, M.; Deris, F. Anti-amnesic activity of Citrus aurantium flowers extract against scopolamine-induced memory impairments in rats. Neurol Sci 2015, 36, 553-560. [CrossRef]

31. Alvarez-Jimenez, R.; Groeneveld, G.J.; van Gerven, J.M.; Goulooze, S.C.; Baakman, A.C.; Hay, J.L.; Stevens, J. Model-based exposure-response analysis to quantify age related differences in the response to scopolamine in healthy subjects. Br. J. Clin. Pharmacol. 2016, 82, 1011-1021. [CrossRef] 
32. Balaban, H.; Naziroglu, M.; Demirci, K.; Ovey, I.S. The protective role of selenium on scopolamine-induced memory impairment, oxidative stress, and apoptosis in aged rats: The involvement of TRPM2 and TRPV1 channels. Mol. Neurobiol. 2017, 54, 2852-2868. [CrossRef]

33. Cutuli, D.; Foti, F.; Mandolesi, L.; De Bartolo, P.; Gelfo, F.; Federico, F.; Petrosini, L. Cognitive performances of cholinergically depleted rats following chronic donepezil administration. J. Alzheimers Dis. 2009, 17, 161-176. [CrossRef] [PubMed]

34. Garibotto, V.; Tettamanti, M.; Marcone, A.; Florea, I.; Panzacchi, A.; Moresco, R.; Virta, J.R.; Rinne, J.; Cappa, S.F.; Perani, D. Cholinergic activity correlates with reserve proxies in Alzheimer's disease. Neurobiol. Aging 2013, 34, 2613-2698. [CrossRef] [PubMed]

35. Lee, S.; Kim, J.; Seo, S.G.; Choi, B.R.; Han, J.S.; Lee, K.W.; Kim, J. Sulforaphane alleviates scopolamine-induced memory impairment in mice. Pharmacol. Res. 2014, 85, 23-32. [CrossRef] [PubMed]

36. Song, S.H.; Choi, S.M.; Kim, J.E.; Sung, J.E.; Lee, H.A.; Choi, Y.H.; Bae, C.J.; Choi, Y.W.; Hwang, D.Y. Alpha-Isocubebenol alleviates scopolamine-induced cognitive impairment by repressing acetylcholinesterase activity. Neurosci. Lett. 2017, 638, 121-128. [CrossRef] [PubMed]

37. Fan, Y.; Hu, J.; Li, J.; Yang, Z.; Xin, X.; Wang, J.; Ding, J.; Geng, M. Effect of acidic oligosaccharide sugar chain on scopolamine-induced memory impairment in rats and its related mechanisms. Neurosci. Lett. 2005, 374, 222-226. [CrossRef] [PubMed]

38. Budzynska, B.; Boguszewska-Czubara, A.; Kruk-Slomka, M.; Skalicka-Wozniak, K.; Michalak, A.; Musik, I.; Biala, G. Effects of imperatorin on scopolamine-induced cognitive impairment and oxidative stress in mice. Psychopharmacology 2015, 232, 931-942. [CrossRef]

39. Tuppo, E.E.; Forman, L.J. Free radical oxidative damage and Alzheimer's disease. J. Am. Osteopath. Assoc. 2001, 101, S11-S15.

40. Wang, G.; Fang, H.; Zhen, Y.; Xu, G.; Tian, J.; Zhang, Y.; Zhang, D.; Zhang, G.; Xu, J.; Zhang, Z.; et al. Sulforaphane prevents neuronal apoptosis and memory impairment in diabetic rats. Cell. Physiol. Biochem. 2016, 39, 901-907. [CrossRef]

41. Rossi, C.; Angelucci, A.; Costantin, L.; Braschi, C.; Mazzantini, M.; Babbini, F.; Fabbri, M.E.; Tessarollo, L.; Maffei, L.; Berardi, N.; et al. Brain-derived neurotrophic factor (BDNF) is required for the enhancement of hippocampal neurogenesis following environmental enrichment. Eur. J. Neurosci. 2006, 24, 1850-1856. [CrossRef]

42. Bartolotti, N.; Bennett, D.A.; Lazarov, O. Reduced pCREB in Alzheimer's disease prefrontal cortex is reflected in peripheral blood mononuclear cells. Mol. Psychiatr. 2016, 21, 1158-1166. [CrossRef]

43. Ambrogini, P.; Cuppini, R.; Cuppini, C.; Ciaroni, S.; Cecchini, T.; Ferri, P.; Sartini, S.; Del Grande, P. Spatial learning affects immature granule cell survival in adult rat dentate gyrus. Neurosci. Lett. 2000, 286, 21-24. [CrossRef]

44. Jain, V.; Baitharu, I.; Prasad, D.; Ilavazhagan, G. Enriched environment prevents hypobaric hypoxia induced memory impairment and neurodegeneration: role of BDNF/PI3K/GSK3beta pathway coupled with CREB activation. PLoS ONE 2013, 8, e62235. [CrossRef]

45. Wu, H.; Lu, D.; Jiang, H.; Xiong, Y.; Qu, C.; Li, B.; Mahmood, A.; Zhou, D.; Chopp, M. Simvastatin-mediated upregulation of VEGF and BDNF, activation of the PI3K/Akt pathway, and increase of neurogenesis are associated with therapeutic improvement after traumatic brain injury. J. Neurotrauma 2008, 25, 130-139. [CrossRef]

46. Ramalingayya, G.V.; Nampoothiri, M.; Nayak, P.G.; Kishore, A.; Shenoy, R.R.; Mallikarjuna Rao, C.; Nandakumar, K. Naringin and rutin alleviates episodic memory deficits in two differentially challenged object recognition tasks. Pharmacogn. Mag. 2016, 12, S63-S70.

47. Khan, M.M.; Ahmad, A.; Ishrat, T.; Khuwaja, G.; Srivastawa, P.; Khan, M.B.; Raza, S.S.; Javed, H.; Vaibhav, K.; Khan, A.; et al. Rutin protects the neural damage induced by transient focal ischemia in rats. Brain Res. 2009, 1292, 123-135. [CrossRef]

48. Javed, H.; Khan, M.M.; Ahmad, A.; Vaibhav, K.; Ahmad, M.E.; Khan, A.; Ashafaq, M.; Islam, F.; Siddiqui, M.S.; Safhi MM et, a.l. Rutin prevents cognitive impairments by ameliorating oxidative stress and neuroinflammation in rat model of sporadic dementia of Alzheimer type. Neuroscience 2012, 210, 340-352. [CrossRef] 
49. Rogerio, A.P.; Kanashiro, A.; Fontanari, C.; da Silva, E.V.; Lucisano-Valim, Y.M.; Soares, E.G.; Faccioli, L.H. Anti-inflammatory activity of quercetin and isoquercitrin in experimental murine allergic asthma. Inflamm. Res. 2007, 56, 402-408. [CrossRef]

50. Jung, S.H.; Kim, B.J.; Lee, E.H.; Osborne, N.N. Isoquercitrin is the most effective antioxidant in the plant Thuja orientalis and able to counteract oxidative-induced damage to a transformed cell line (RGC-5 cells). Neurochem. Int. 2010, 57, 713-721. [CrossRef]

51. Hassan, W.; Rongyin, G.; Daoud, A.; Ding, L.; Wang, L.; Liu, J.; Shang, J. Reduced oxidative stress contributes to the lipid lowering effects of isoquercitrin in free fatty acids induced hepatocytes. Oxid. Med. Cell. Longev. 2014, 2014, 313602. [CrossRef]

52. Valentova, K.; Vrba, J.; Bancirova, M.; Ulrichova, J.; Kren, V. Isoquercitrin: pharmacology, toxicology, and metabolism. Food Chem. Toxicol. 2014, 68, 267-282. [CrossRef]

53. Ip, P.S.; Tsim, K.W.; Chan, K.; Bauer, R. Application of complementary and alternative medicine on neurodegenerative disorders: current status and future prospects. Evid. Based Complement. Alternat. Med. 2012, 2012, 930908. [CrossRef]

54. Dai, Q.; Borenstein, A.R.; Wu, Y.; Jackson, J.C.; Larson, E.B. Fruit and vegetable juices and Alzheimer's disease: The Kame Project. Am. J. Med. 2006, 119, 751-759. [CrossRef]

55. Dayanc, M.; Kibar, Y.; Irkilata, H.C.; Gok, F.; Tahmaz, L.; Ors, O.; Akyol, I. A new modification of dismembered pyeloplasty for primary ureteropelvic junction obstruction. Eur. Surg. Res. 2008, 40, 225-229. [CrossRef]

56. Zhang, S.J.; Luo, D.; Li, L.; Tan, R.R.; Xu, Q.Q.; Qin, J.; Zhu, L.; Luo, N.C.; Xu, T.T.; Zhang, R.; et al. Ethyl acetate extract components of bushen-yizhi formula provides neuroprotection against scopolamine-induced cognitive impairment. Sci. Rep. 2017, 7, 9824. [CrossRef]

(C) 2019 by the authors. Licensee MDPI, Basel, Switzerland. This article is an open access article distributed under the terms and conditions of the Creative Commons Attribution (CC BY) license (http://creativecommons.org/licenses/by/4.0/). 